\section{More plans for malaria vaccine}

\section{Bogotá}

Colombia, hitherto best known for its coffee, now seeks to cultivate a reputation in science. As his last act in support of science, outgoing President Belisario Betancur earlier this month announced a

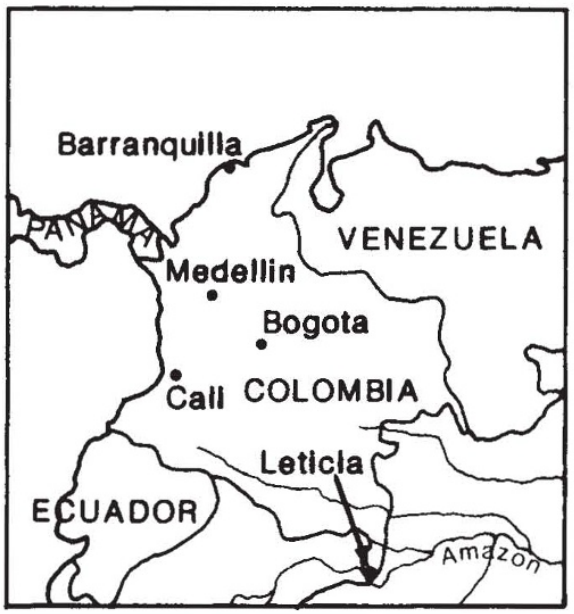

scheme whereby six of Colombia's best science graduates at a time would be awarded fellowships to study at the $\mathrm{Re}$ search Institute of Scripps Clinic in California.

As the students will be paid from Colombia, they will be obliged to return there after their three-year stints in Richard Lerner's department of molecular biology at Scripps.

The hope is to increase Colombia's abilities in modern biomedical research, now concentrated in Manuel Patarroyo's Institute of Immunology at the San Juan de Dios Hospital in Bogotá.

Patarroyo, with the aid of the presidency and particularly of one of its economic advisers, Diego Pizano, whose support of science stems from a friendship with French virologist Gerard Bricogne while both were studying at the University

\section{Catch your monkey}

Aotus monkeys are collected by Indians in the Amazonian basin. With a group of monkeys inside the hollow tree trunks that they live in, the Indians first seal off all the exit holes. They then reopen one hole and as the enraged animals emerge, try to catch them by the tail.

It can take a week to catch a single animal. Captured monkeys are taken to Leticia at the southernmost tip of Columbia, where the malaria trials are carried out. Because the Aotus monkey is a protected species, those that succumb to malaria have to be cured with drugs. They are then passed on to a breeding colony elsewhere in Colombia and, sometimes, released back into the wild. of Cambridge, together with a gift of several sequencing and synthesizing machines from Arnold Beckman, has set up what is probably the best-equipped biomedical laboratory in South America.

Patarroyo, together with approximately thirty enthusiastic young researchers, is beginning to pursue gene cloning and vaccine development for malaria, leprosy and tuberculosis. They do so against the odds. For example, customs and other delays tend to allow "hot" radioisotopes to become cold and heat-degradable enzymes to warm up before they reach the institute. And there is no adequate postgraduate research programme in Colombia.

On the other hand, Colombians do have the advantage over laboratories in North America and Europe of having easy access to malaria and leprosy patients and to the animal models for the diseases, the Aotus monkey and the armadillo, respectively.

The most important outcome of the institute's research so far is the development of a candidate malaria vaccine. Reporting the initial data on the vaccine at a conference entitled Perspectives for Chemistry in Medicine in Bogotá this month, Patarroyo described how the immunization of monkeys with a combination of three synthetic peptides, corresponding to partial sequences of one of the major proteins on the surface of malarial red blood cells, protects the animals against infection with the protozoan Plasmodium falciparum, which is the main malaria parasite of humans.

So far the tests have involved only a few monkeys, but up to 50 will be included in an extended trial.

About a thousand scientists and students attended the conference. According to the organizers, Patarroyo and Pizano, the main purpose was to provide a stimulus to Colombian science, which came in the form of 10 speakers from the United States and 4 from Europe

Four of the speakers, Lerner plus Gobind Khorana of Massachusetts Institute of Technology, David Baltimore of the Whitehead Institute and Peter Perlmann of the University of Stockholm, were awarded the Order of San Carlos in the rank of knight by President Betancur during the conference.

Should an effective malaria vaccine emerge - and even with the first phase of clinical trials of some possible vaccine components about to begin in other countries, nobody doubts that there is a long way to go - Colombia should be well placed to carry out a mass vaccination campaign.

During 1985 and early 1986, several million young children were vaccinated against five common diseases by means of a campaign that involved the newspaper El Tiempo, the radio network Caracol, UNICEF, the Roman Catholic Church, the armed forces, various government agencies and a host of volunteers.

The only part of the country to be missed out, a strip of inaccessible Pacific coastland, is about to be tackled in a week of action involving 100 helicopters and hundreds of boats. Peter Newmark

\section{Coffee benefaction}

As coffee is far and away Colombia's main export, it is not surprising that the Feder ación Nacional de Cafeteros de Colombia maintains two laboratories, one that concentrates on the chemistry and the other on the biology of coffee.

The chemistry laboratory in Bogotá under Marco Quijano employs approximately twenty scientists and seventy students to study coffee composition and processing as well as tissue culture and the problems of coffee rust, a fungal disease that reached Colombia only in the past two or three years.

Copper-containing sprays are the main way to defeat the rust fungus but they are expensive to administer, not least because they have to be delivered by hand as aerial spraying would ruin the electricity cables. The chemistry laboratory is conducting a careful study of the effects of copper on the coffee plant, to establish whether it would be possible to treat the soil with copper to inhibit rust disease. In the end, however, Quijano believes that the fungus will develop resistance to copper.

Studies of coffee processing are a particular focus of the laboratory because of the growing demand for decaffeinated coffee in the developed nations. There has been talk of using biotechnology genetically to manipulate the coffee plant so that the beans are caffeine-free. But in economic terms, this makes little sense, because the process of decaffeination is paid for by the sale of the caffeine to the pharmaceutical industry. Cloning of coffee plants, on the other hand, is considered important and 250 plants derived by tissue culture are being studied.

Colombian coffee tends to be sold at a premium price because it is made from ripe beans only. That is possible because the beans are hand-picked rather than mechanically shaken from the plants. This fits with the fact that Colombian coffee is largely grown on small plots owned by a single family which receives a guaranteed price from the coffee growers' association to whom they have to sell their crop. This provides a buffer against bad years, but also means that the farmers are not benefiting from this year's high prices, occasioned by the failure of the Brazilian crop. 